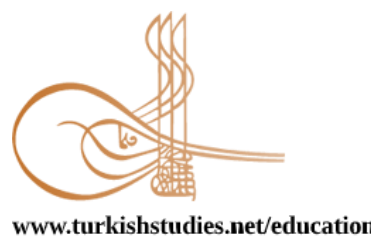

Turkish Studies - Educational Sciences

eISSN: 2667-5609

Sponsored by IBU

Research Article / Araștırma Makalesi

\title{
Özel Yeteneklilerin Eğitiminde Erken Müdahale Uygulamaları
}

\author{
Early Intervention in Gifted Education*
}

Filiz Karadağ $^{* *}$ - Vesile Yıldız Demirtaş ${ }^{* * *}$

\begin{abstract}
The development of linguistic skills, motor skills, cognitive skills, academic skills, music and arts, and personal or interpersonal skills may be significantly ahead in some children in early childhood. The characteristics of these children, who are defined as gifted, in early childhood, language skills including advanced vocabulary according to age, and the ability to use the language in an original and meaningful way, asynchronous development, emotional sensitivity, early awareness of differences, playing cooperative games, using unusual objects in their games is leadership, enhanced humor ability, sensitivity to problems, curiosity, cognitive skills, metacognitive control, academic success, early reading. Early intervention is a variety of activities designed to support the development of young children. Early intervention generally begins with a comprehensive assessment of the strengths and needs of the child and family. As the child develops, it expands through the provision of appropriate support and services for active monitoring and reevaluation. It is seen that the need for early intervention programs is foreseen in the training of gifted, but a few studies has been done for this. It was observed that this need was met with a small amount of time, and different early intervention models, especially Illionis University, were introduced. In this direction, the aim of the study is to determine the early intervention methods they need and to reveal the existing needs, based on the early characteristics of gifted individuals.
\end{abstract}

Structured Abstract: The development in linguistic skills, motor skills, cognitive skills, academic skills, music and arts, and personal or interpersonal skills can be significantly advanced in some children in early childhood (Olszewski-Kubilius, Limburg-Weber, \& Pfeiffer, 2003). One of the first and most effective studies to determine the characteristics of these children, who are defined as special talent, in early childhood, is Terman's longitudinal study with 1528 children with 135 or higher IQ. According to the study of Terman (1925), specially talented children walk about a month ago compared to their moderately talented peers and their language development is 3.5 months ahead. At the same time, it was revealed that approximately $50 \%$ of specially gifted children in the study were able to read before starting school (Shurkin, 1992).

\footnotetext{
${ }^{*}$ Arş. Gör. Filiz Karadağ’ın Doktora Tezinden yararlanılmıştır.

*** Arş. Gör. Filiz Karadağ, Dokuz Eylül Üniversitesi, Buca Eğitim Fakültesi, Özel Eğitim Bölümü Research Assistant Filiz Karadă̆, Dokuz Eylül Universtiy, Special Education Department ORCID 0000-0003-4024-7852

filiz.karadag@deu.edu.tr

**** Prof. Dr. Vesile Yıldız Demirtaş, Dokuz Eylül Üniversitesi, Buca Eğitim Fakültesi, Özel Eğitim Bölümü

Prof. Dr. Vesile Ylldız Demirtaş, Dokuz Eylül Universtiy, Special Education Department

ORCID 0000-0003-4024-7852

yildiz.vesile@gmail.com; vesile.yildiz@deu.edu.tr
}

Cite as/ Atıf: Karadăg, F. \& Yıldız Demirtaş, V. (2020). Özel yeteneklilerin eğitiminde erken müdahale uygulamaları. Turkish Studies - Education, 15(4), 2721-2740. https://dx.doi.org/10.47423 /TurkishStudies.42044

Received/Geliș: 06 March/Mart 2020

Accepted/Kabul: 21 June/Haziran 2020

Copyright C INTAC LTD, Turkey 
According to the researches made in recent years, specially gifted children in preschool period have features that distinguish them from their peers. Cognitive features such as rapid learning, improved memory, ability to understand complex concepts and high observation ability became evident in the first years (Clark, 2002; Harrison, 2003; Robinson, 2008; Sutherland, 2008). Similarly, socio-emotional characteristics such as advanced humor ability, sensitivity, social maturity, empathy and advanced play patterns are frequently seen in specially gifted young children (Clark, 2013; Harrison, 2003). In addition, they can perform well in language skills, motor skills, academic skills, music and arts, personal or interpersonal skills (Olszewski- Kubilius, Limburg-Weber, \& Pfeiffer, 2003).

Cukierkorn, Karnes, Manning, Houston \& Besnoy (2008) summarized the characteristics of specially gifted children in preschool period, their comments and exemplary situations in their study. Accordingly, the general characteristics of specially gifted children in preschool are listed below.

1. Language skill including advanced vocabulary by age and the ability to use the language in an original and meaningful way: While this skill has made the first verbal experiences of peers, verbal communication with parents of specially talented children, actively using the language to express themselves, to obtain information allows them to use the language to ask questions.

2. Asynchronous development: Cognitive, motor and social-emotional development of children does not generally develop synchronously.

3. Emotional sensitivity: Children are very sensitive to the feelings of themselves and others. This situation provides a rapid development of value, empathy and responsibility awareness.

4. Early awareness of differences: The potential to develop perfectionism characteristics may result from the ability of specially talented children to judge themselves with their peers' performance in addition to their own expectations.

5. Cooperative play: Children often undertake the tasks of starting play sessions, coordinating and integrating many complementary roles, taking into account the behavior of other children.

6. Using unusual objects in their games: Due to this feature of the children, the environmental environment prepared for them should be prepared well by offering more stimulants.

7. Leadership: Children are preferred by other friends to make friends, share ideas and make decisions.

8. Improved humor ability: Children can respond to riddles and verbal connotations, rather than visual humor, often found in children's books of their age.

9. Sensitivity to problems: This feature may cause suspicion, fear and feelings of guilt because of the missing or wrong understanding of children with special abilities.

10. Curiosity: Children with special abilities gain many interests with curiosity. This enables them to easily add the information they obtain to their knowledge.

11. Cognitive skills: Children show evidence of self-involvement of reasoning, logical thinking, creativity and academic activities in free play.

12. Metacognitive control: Children develop economic and effective cognitive strategy when solving problems.

13. Academic success: Children are very successful in deciphering symbolic expressions such as remembering complex information, map and written language.

14. Early reading: Since children make it easier to understand, according to their peers, they can read the texts quickly, both loudly and quietly.

In the study conducted by Walsh, Kemp, Hodge \& Bowes (2012) for the purpose of examining educational interventions for special talent, it was revealed that although there is a consensus on the need for special talented children in preschool education, it is one of the groups that receive the least service in education. Karnes \& Johnson (1991) stated that the need for these early intervention programs has been eliminated over time, and different early intervention models, especially Illionis University, have been introduced. Looking at the content of these education models (Camp, 1963; Ehrlich, 1978; Karnes \& Johnson, 
1991; Kitano \& Kerby, 1986; Robinson \& Roedell, 1980; Swassing, 1985), Bloom taxonomy model is widely used and questioning, creative thinking, critical thinking and it is seen that content to develop problem solving skills is created. Focusing on developing these skills in early childhood will support children's leading cognitive development (Karnes \& Johnson, 1991). An important goal of early childhood education is to improve the preconditions that will be needed in school and in future success by providing children with cognitive skills and socialization (Pianta, Barnett, Burchinal \& Thornburg, 2009). To achieve this goal, researchers suggest that early childhood programs should be child-focused, established, highly contextual, meaningful interactions, teacher-guided, concentrated and open to key concepts. (Ginsburg \& Golbeck, 2004; Justice \& Kaderavek, 2004).

Keywords: Special Education, Early İntervention, Special Ability, Giftedness, Preschool Period

Öz: Erken çocukluk döneminde bazı çocukların bilişsel, dil, psiko-motor ve sosyal beceriler ile müzik ve sanat alanında gelişimi daha ileri düzeyde olabilmektedir. Özel yetenekli olarak tanımlanan bu çocukların erken çocukluk dönemindeki özellikleri, yaşına göre ileri düzey kelime bilgisini kapsayan dil becerisi ile dili orijinal ve anlamlı şekilde kullanma becerisi, senkronize olmayan gelişim, duygusal hassasiyet, farklılıklara yönelik erken farkındalık, işbirlikli oyun oynama, oyunlarında alışılmadık nesneler kullanma, liderlik, gelişmiş mizah yeteneği, sorunlara duyarlılık, merak, bilişsel beceriler, üst bilişsel kontrol, akademik başarı, erken okumadır. Erken müdahale, küçük yaştaki çocukların gelişimini desteklemek üzere tasarlanmış çeşitli aktivitelerdir. Erken müdahale, genel olarak, çocuk ile ailenin güçlü yönlerinin ve ihtiyaçlarının kapsamlı bir şekilde değerlendirilmesi ile başlar. Çocuk geliştikçe, aktif izleme ve yeniden değerlendirmeye yönelik uygun desteklerin ve hizmetlerin sağlanması yoluyla genişler. Özel yeteneklilerin eğitiminde erken müdahale programlarına olan ihtiyacın öngörüldüğü ancak buna yönelik oldukça az çalışma yapıldığı görülmektedir. Bu ihtiyacın zamanla az da olsa giderildiğini ve Illionis Üniversitesi başta olmak üzere birbirinden farklı erken müdahale modellerine yer verilmeye başlandığını görülmüştür. Bu doğrultuda çalışmanın amacı özel yetenekli bireylerin erken dönemdeki özelliklerinden yola çıkılarak ihtiyaç duydukları erken müdahale yöntemlerinin belirlenmesi ve var olan ihtiyacın ortaya konulmasıdır. Bu doğrultuda erken çocukluk döneminde özel yetenekli çocukların özellikleri, eğitimi ve erken müdahale yaklaşımlarına yer verilmiştir.

Anahtar Kelimeler: Özel Eğitim, Erken Müdahale, Özel Yetenek, Üstün Yetenek, Okul Öncesi Dönem

\section{Giriş \\ Okulöncesi Dönem/Erken Çocuklukta Özel Yetenekli Çocukların Özellikleri}

Okul öncesi dönemdeki özel yetenekli çocuklar ileri veya hızlı gelişmeleri nedeniyle yüksek düzeyde performans gösterme potansiyeli olan çocuklar olarak tanımlanmaktadır (Bullmore, SerraGrabulosa, Romero-Garcia, Vilaseca, Adan, Vilaró \& Bargalló, 2019; Clark, 2002; Cukierkorn, Karnes, Manning, Houston \& Besnoy, 2008; Cross, 2017;Harrison, 2004; Morelock, Brown, \& Morrissey, 2003; Smutny, 1998). Benzer şekilde araştırmacılar, okul öncesi dönemdeki özel yetenekli çocukları, ilgi alanlarına yoğunlaşan, meraklı, ısrarcı ve öğrenmede soyut bağlantılar kurabilen düşünürler olarak tanımlanmıştır (Louis \& Lewis, 1992; Roedell, 1989; Solé-Casals, SerraGrabulosa, Romero-Garcia, Vilaseca, Adan, Vilaró \& Bullmore, 2019; Tuttle, Becker \& Sousa, 1988; Webb, Meckstroth \& Tolan, 1982).

Okul öncesi dönemdeki özel yetenekli çocuklar, onları yaşıtlarından ayıran bazı özelliklere sahiptir. Hızlı öğrenme, gelişmiş hafıza, karmaşık kavramları anlama yeteneği ve yüksek gözlem yeteneği gibi bilişsel özellikler ilk yıllarda belirgin hale gelmektedir (Clark, 2002; Harrison, 2003; Robinson, 2008; Sutherland, 2008). Benzer şekilde, ileri düzey bir mizah yeteneği, duyarlılık, sosyal olgunluk, empati kurabilme ve gelişmiş oyun kalıpları gibi sosyo-duygusal özellikler de özel yetenekli küçük çocuklarda sıkça görülmektedir (Clark, 2013; Harrison, 2003). Bununla birlikte dil becerileri, motor beceriler, akademik yetenek, müzik ve sanat, kişisel ya da kişilerarası becerilerde de yüksek performans gösterebilirler (Olszewski- Kubilius, Limburg-Weber, \& Pfeiffer, 2003). 
Okul öncesi dönemdeki özel yetenekli çocukların genel özellikleri aşağıda listelenmiştir:

1.Yaşına göre ileri düzey kelime bilgisi ile dili orijinal ve anlamlı şekilde kullanma becerisi: $\mathrm{Bu}$ beceri akranları henüz ilk sözel deneyimlemelerinde bulunurken, özel yetenekli çocukların ebeveynleri ile sözel iletişim kurma, kendini ifade etmek için dili aktif şekilde kullanma, uzun cümleler kurma, bilgi almak için soru sorma amacıyla dili kullanmalarını kapsamaktadır. (Cukierkorn, Karnes, Manning, Houston \& Besnoy, 2008, Eby \& Smutny, 1991; Kitano, 1985; Perleth, Lehwald, \& Browder, 1993. Schnur \& Lowrey 1986).

2. Senkronize olmayan gelişim: Çocukların bilişsel, motor ve sosyal-duygusal gelişimi genel olarak senkronize bir şekilde gelişmemektedir (Cukierkorn, Karnes, Manning, Houston \& Besnoy, 2008)

3. Duygusal hassasiyet: Çocuklar kendilerinin ve diğerlerinin hislerine karşı oldukça hassastır. $\mathrm{Bu}$ durum değer, empati ve sorumluluk bilincinin hızlı bir şekilde gelişmesini sağlamaktadır (Cukierkorn, Karnes, Manning, Houston \& Besnoy, 2008).

4. Farklılıklara yönelik erken farkındalık: Özel yetenekli çocuklar bu nedenle akranlarına oranla daha erken sosyal karşılaştırmalar yapabilirler (Abroms, 1981; Feldhusen, \& Kolloff, 1979; Robinson, 1993).

5. Gelişmiş sosyal beceriler: Çoğunlukla bu beceriye sahip özel yetenekli çocuklar, sağlıklı oyun ve etkileşim kurarlar (Morelock, Brown \& Morrissey, 2003; Wright, 1990). Özel yetenekli küçük çocuklar, sahip oldukları gelişkin hafıza sayesinde sosyal etkileşimlerini de iyi yönetebilmektedirler (Abroms, 1981).

6. İşbirlikli oyun oynama: Çocuklar genellikle diğer çocukların davranışlarını göz önünde bulundurarak oyunu başlatma, birçok tamamlayıcı rolü koordine etme ve bütünleştirme görevlerini üstlenmektedir (Cukierkorn, Karnes, Manning, Houston \& Besnoy, 2008).

7. Oyunlarında alışılmadık nesneler kullanma: Çocukların bu özelliği nedeniyle onlar için hazırlanan çevresel ortamın fazla uyarıcı sunarak iyi hazırlanması gerekmektedir. (Cukierkorn, Karnes, Manning, Houston \& Besnoy, 2008).

8. Liderlik: Çocuklar diğer arkadaşları tarafindan arkadaşlık kurma, fikir paylaşma ve karar alma konusunda tercih edilmektedir (Cukierkorn, Karnes, Manning, Houston \& Besnoy, 2008).

9. Gelişmiş mizah yeteneği: Özel yetenekli çocuklar, genellikle kendi yaş düzeylerindeki çocuk kitaplarında bulunan görsel mizah yerine bilmecelere ve sözel çağrışımlara cevap verebilmektedirler (Cukierkorn, Karnes, Manning, Houston \& Besnoy, 2008).

10. Sorunlara duyarlılık: Özel yetenekli çocuklar sorunlar karşısında eksik bir bilgilendirmede veya yanlış anlaşılma durumunda şüphe, korku ve suçluluk duyguları hissetedebilmektedirler(Cukierkorn, Karnes, Manning, Houston \& Besnoy, 2008).

11. Duygusal hassasiyet: Bu özellik özel yetenekli çocukların değer, empati ve sorumluluk duygularının daha erken gelişmesini sağlamaktadır (Clark, 2002).

12. Merak: Özel yetenekli çocuklar meraklı ve birçok alana ilgilidir. Bu durum onların elde ettikleri bilgileri kendi bilgi birikimlerine kolayca eklemelerini sağlamaktadır (Cukierkorn, Karnes, Manning, Houston \& Besnoy, 2008).

13. Bilişsel beceriler: Özel yetenekli çocukların erken dönemde hızlı öğrenme, gelişmiş hafıza, karmaşık kavramları anlama ve gözlem yapma yeteneği gibi bilişsel özellikleri belirgindir. Bunun dışında muhakeme, mantıksal düşünme, yaratıcılık ve akademik aktiviteleri kendiliğinden serbest oyuna dahil edebilmektedirler (Clark, 2002; Harrison, 2003; Robinson, 2008; Sutherland, 2008, Kitano 1985). 
14. Üst bilişsel kontrol: Özel yetenekli çocuklar problem çözerken etkili bilişsel strateji geliştirmektedir (Perleth, Lehwald, \& Browder, 1993).

15. Akademik başarı: Özel yetenekli çocuklar karmaşık bilgileri hatırlama, harita ve yazı dili gibi sembolik ifadeleri deşifre etmekte oldukça başarılıdır (Cukierkorn, Karnes, Manning, Houston \& Besnoy, 2008).

16. Erken okuma: Çocuklar anlamayı kolaylaştırdığı için akranlarına göre erken dönemde hem sesli hem sessiz bir şekilde metinleri hızlıca okuyabilmektedir (Cukierkorn, Karnes, Manning, Houston \& Besnoy, 2008)

\section{Okul Öncesi Dönemdeki Özel Yetenekli Çocukların Eğitimi}

Erken çocukluk döneminde gelişimdeki kritik dönemler ve çocukların bireysel farklılıkları göz önüne alındığında bu dönemde alınan eğitimin çocuğun tüm gelişim alanlarını etkileyen kritik bir süreç olduğu görülmektedir (Emre, 2017; Magnuson, Meyers, Ruhm \& Waldfogel, 2004; Pianta, Barnett, Burchinal \& Thornburg, 2009; Peyre, Ramus, Melchior, Forhan, Heude, Gauvrit \& EDEN, 2016). Bu dönemdeki özel yetenekli çocukların eğitimi, öğrenme özellikleri ve farklı alanlardaki gelişim özelliklerine uygun bir anlayışa dayandırılmalıdır. Bu noktada okul öncesindeki özel yetenekli çocuklara hizmet vermenin önemli etkileri olduğu ve hem erken çocukluk hem de özel yeteneklilerin eğitimi alanlarındaki bilgilerin bir araya getirilmesinin gerekliliği karşımıza çımaktadır (Barbour, 1992; Barbour \& Shaklee, 1998; Belova, 2019; Hodge \& Kemp, 2000; Karnes, Manning, Besnoy, Cukierkorn, \& Houston, 2005; Margrain \& Lundqvist, 2019; Snowden, 1995; Walker, Hafenstein, \& Crow-Enslow, 1999).

Erken çocukluk dönemindeki yetenek eğitimi, entelektüel gelişimin sağlanması ve anlamlı aktiviteler sunulması etrafinda döner. Bu tür eğitim süreçleri, öğretmen tarafından başlatılan ve öğrencilerin aktif katılımıyla çocuğun dünyayı keşfettiği aktivitelere dayanan zengin öğrenme süreçleridir (Miller \& Almon, 2009). Okul öncesi dönemde yetenek gelişimi için öğretmenler, yöneticiler ve eğitim koordinatörleri sadece geleneksel akademik beceri kazanımına odaklanan öğretimsel süreçleri değiştirmekle kalmayarak, özel yeteneklilik ve yeteneğin nasıl tanımlanması ve ele alınması gerektiği konusundaki düşünce ve varsayımlarını da değiştirmelidirler (Kaplan \& Hertzog, 2016). Miller \& Almon (2009)'un on ülkede 1500'den fazla okul öncesi dönemdeki çocukla yaptığı çalışmada, her ülkede, çocukların dil performanslarının, öğretmenlerin çocuklarını akademik dersler almaktan ziyade etkinliklerini seçmelerine izin verdiğinde geliştiğini tespit etmiştir. Aynı çalışmada, bu çocukların yaşında bilişsel performansın, büyük grup etkinliklerinde daha az, bireysel veya küçük gruplarda çalışırken daha fazla geliştiği tespit edilmiştir.

Tipik olarak, okul öncesi öğretmenliği eğitiminde, özel yetenekli çocukların okul öncesi eğitim ortamına nasıl entegre edebileceği veya bu çocukların ihtiyaçlarının eğitsel, sosyal veya duygusal olarak nasıl karşılanabileceği konusunda çok az bilgi bulunmaktadır (Hodge, 2013). Bu nedenle, entelektüel anlamda özel yetenekli küçük yaştaki çocuklar, eğitimde en çok ihmal edilen gruplardan biri olarak gösterilmektedir (Koshy \& Robinson, 2006).

Erken çocukluk dönemindeki özel yetenekli çocuklar için uygun eğitim sunmak birçok nedenden dolayı önemlidir. Bunlardan ilki, tüm çocukların yetenek düzeyleri göz ardı edilerek aynı okul öncesi eğitim ortamında eğitim almasıdır. İkincisi, entelektüel olarak zorlanmayan genç yetenekli çocukların, hâlihazırda üstlendikleri görevlerin tekrarlanmasından dolayı sıkıntı tehlikesiyle karşı karşıya kalmaları ve bu durumun başarısızlığa yol açabilecek olmasıdır. Üçüncüsü ise, küçük yaştaki özel yetenekli çocukların değerli birer doğal kaynak olması ve toplumun gelecekteki yararı için yeteneklerini geliştirmeye önem verilmesi gerekliliğidir (Margrain \& Lundqvist, 2019; Schwartz, 1994). 
Erken çocukluk döneminde özel yeteneklilerin eğitimi üç kritik faktör ile çevrelenmiştir. Bunlar;

- Tüm çocuklar, zorluk içeren görevler edinmelidir.

• Görev, öğretmen ve öğrenciler için onların güçlü yönlerini, ihtiyaçlarını ve ilgi alanlarını tanımalarını sağlamalıdır.

- İhtiyaç ve ilgi alanlarını tanımak için bağlamlar oluşturan öğretmenler, öğrenciler arasındaki hazır bulunuşluk düzeyi farklılıklarına yanıt vermelidir (Kaplan \& Hertzog, 2016).

Kaplan \& Hertzog (2016)'e göre, okul öncesi dönemdeki özel yetenekli çocuklara yönelik öğretim programlarında eğitimciler, çocukların fikirlerini ve ilgi alanlarını keşfetmeyi sağlayarak çocukları, düşüncelerini geliştirmeye teşvik etmelidir. Bunu sağlamak için öğrencilerin ihtiyaçlarını, ilgi alanlarını ve güçlü yanlarını keşfetmelidir. Bu çocukların potansiyel yeteneklerini geliştirmek amacıyla bir katalizör görevi gören öğrenme süreçleri tasarlanmalıdır. Bu eğitsel süreçte aşağıdaki özelliklere dikkat edilmelidir:

1. Bağımsız araştırmaları teşvik etmek için kaynak (oyun, kitap ve fotoğraf) bulundurulmalıdır.

2. Çocuklara, disiplin içi, disiplinler arası ve tek başına, küçük gruplar halinde veya tüm sinıfla problem çözme firsatları yaratılmalıdır.

3. Öğrencilere, konu ile ilgili hipotezlerde bulunmaları için mevcut bilgilerini kullanma firsatı verilmelidir.

4. Farklılaştırılmış görevlerin bağımsız olarak yürütülmesini sağlayan yetenek, ilgi ve farklı1ıklara yönelik bir eğitim programı sağlanmalıdır (Kaplan \& Hertzog, 2016).

\section{Erken Müdahale ve Önemi}

Erken müdahale, küçük yaştaki çocukların gelişimini desteklemek üzere tasarlanmış çeşitli aktiviteler anlamına gelmektedir (Guralnick \& Bruder, 2019; Ramey \& Ramey, 1998; Walsh, Kemp, Hodge \& Bowes, 2012). Erken müdahale, genel olarak, çocuk ile ailenin güçlü yönlerinin ve ihtiyaçlarının kapsamlı bir şekilde değerlendirilmesi ile başlar. Çocuk geliştikçe, aktif izleme ve yeniden değerlendirmeye yönelik uygun desteklerin ve hizmetlerin sağlanması yoluyla genişler. Uygulamada, erken müdahalenin kapsamında büyük farklılıklar yer alabilmektedir (Guralnick, 2019; Karnes \&Johnson, 1991; Ramey \& Ramey, 1992).

Erken müdahale programlarında, programa katılan özel gereksinimli çocuk ve ailesinin ihtiyaçları, müdahale bileşenleri ve beklenen gelişimsel ilerlemeyi veya sonuçları belirleyen bireyselleştirilmiş bir plan yer almaktadır. Bu planlar profesyoneller ve ebeveynler tarafından işbirliği içinde geliştirilmeli ve en az yılda bir kez güncellenmelidir. Çocuk ve aile düzeyinde başarı, ailenin ve erken müdahale uygulayıcılarının çocuk için oluşturduğu beklentilerle tanımlanmaktadır (Ramey \& Ramey, 1998).

Erken müdahale programları, ailelere ve çocuklara yönelik olmak üzere iki farklı şekilde uygulanmaktadır. Ailelere yönelik çalışmalar, yetişkin eğitimi, meslek eğitimi, sosyal-duygusal destek, ebeveynlik becerileri eğitimi ve sağlık hizmetleri şeklinde yapılmaktadır. Çocuklara yönelik erken müdahale programları ise, öğrenme ve eğitim destekleri, çocuk bakımı, duygusal destek, psikolojik destek ve sağlık hizmetleri şeklinde yapılmaktadır. Etkili bir erken müdahale programının temel kriterleri, zamanlama ve sürenin doğru ayarlanmas1, eğitimin yoğunluğu, doğrudan strateji kullanımı, esneklik, bireysel farkların gözetilmesi, çevresel etmenler ve kültürel uygunluktur. Erken müdahale programları sürecinde çocuk ve çevresi arasındaki etkileşim, çocuğu temel bilişsel becerilerinin gelişmesine, yeni edinilen becerilerin kullanılmasına, yeni edinilen becerilerin 
aktarılmasına ve çevrenin keşfedilmesine olanak sağlar. Bu sürecin sonunda erken müdahale programının amacı, çocukta bilişsel, sosyal ve duygusal değişimi sağlamaktır (Ramey \& Ramey, 1998).

Bu hedef doğrultusunda erken müdahale programları, aile merkezli, kurum merkezli, kurumaile-toplum merkezli şeklinde uygulanmaktadır. Kurum merkezli programlar bir dönem boyunca uygulanan yoğun programlar iken ev merkezli programlar uzun bir zaman aralığında gerçekleştirilmektedir. Bununla birlikte kurum merkezli programlar sadece çocuğu hedef alırken, ev merkezli programlar çocukla birlikte aileyi de hedef almaktadır. Örneğin, Portage gibi kurum merkezli bir erken müdahale programı bir yıl boyunca, haftanın beş günü uygulanırken, ev merkezli bir program ayda bir kere iki-üç saat şeklinde gerçekleştirilebilmektedir (Morkoç \& Acar, 2014).

Etkili şekilde gerçekleştirilen erken müdahale programlarının çocuk-aile-toplum üçgeninde sosyal ve ekonomik faydaları bulunmaktadır. Bu programların kısa süreli etkilerinin incelendiği çalışmalar, müdahaleden faydalanan çocukların bilişsel, psikomotor ve sosyal gelişimleri ile okul olgunluğu, iletişim, okula uyum gibi becerilerinin müdahaleden yararlanmayan çocuklara göre daha iyi düzeyde olduğunu göstermektedir. Programların uzun süreli etkilerini inceleyen çalışmalar ise müdahaleden faydalanan çocukların akademik becerilerinin, okul başarılarının, eğitsel performanslarının arttı̆̆ını göstermektedir (Morkoç \& Acar, 2014).

Özel yetenekli çocuklar için halihazırda uygulanan erken müdahale programları, çocuklara sunulan eğitim programının seçeneklerini genişletme süreci olan zenginleştirmeyi, zihinsel olarak zorlu materyallerin erken yaşta sunulması ve / veya okula erken yaşta başlamanın sağlanması, benzer entelektüel yetenekleri olan çocukları hem eğitimsel hem sosyo-duygusal hedefler doğrultusunda bir araya getirme şeklinde uygulanmaktadır (Walsh, Kemp, Hodge \& Bowes, 2012).

\section{Özel Yeteneklilerde Erken Müdahale}

Özel yeteneklilere yönelik eğitim müdahalelerin incelenmesi amacıyla Walsh, Kemp, Hodge \& Bowes (2012) tarafindan yapılan çalışmada okul öncesi dönemdeki özel yetenekli çocukların eğitime duyduğu ihtiyaç üzerinde fikir birliği olmasına rağmen eğitimde en az hizmet alan gruplardan biri olduğu ortaya konmuştur. Karnes \& Johnson (1991) bu erken müdahale programlarına olan ihtiyacın zamanla az da olsa giderildiğini ve Illionis Üniversitesi başta olmak üzere birbirinden farklı erken müdahale modellerine yer verilmeye başlandığını belirtmiştir. Bu eğitim modellerinin (Camp, 1963; Bildiren \& Kargın, 2019; Ehrlich, 1978; Karnes \& Johnson, 1991; Kitano \& Kerby, 1986; Robinson \& Roedell, 1980; Swassing,1985) içeriğine bakıldığında Bloom taksonomi modelinin yaygın olarak kullanıldığı ve sorgulama, yaratıcı düşünme, eleştirel düşünme ve problem çözme becerilerini geliştirmeye yönelik içeriklerin oluşturulduğu görülmektedir. Erken çocukluk döneminde bu becerilerin geliştirilmesine odaklanılması, çocukların önde giden bilişsel gelişiminin desteklenmesini sağlayacaktır (Karnes \& Johnson, 1991). Hali hazırda erken çocukluk eğitiminin önemli bir hedefi, çocukların bilişsel becerilerini ve sosyalleşmelerini sağlayarak, okulda ve gelecekteki başarısında ihtiyacı olacak ön koşulların iyileştirilmesidir (Pianta, Barnett, Burchinal \& Thornburg, 2009). Bu hedefe ulaşmak için araştırmacılar, erken çocukluk programlarının çocuk odaklı, yüksek düzeyde bağlamsal, anlamlı etkileşimler içeren, öğretmen rehberli ve anahtar kavramlara açık bir şekilde olmasını önermektedir (Ginsburg \& Golbeck, 2004; Justice \& Kaderavek, 2004).

Özel yetenekli çocuklara yönelik erken müdahale programlarının geliştirilmesini ve uygulanmasını zorlaştıran etmenler Karnes \& Johnson (1991) tarafından aşağıdaki şekilde özetlenmiştir:

1. Ebeveyn Katılımı/İstekliliği Eksikliği: $\mathrm{Bu}$ yaştaki özel yetenekli çocukların ailelerinin, büyük yaş grubundaki çocukların aileleri gibi, çocuklarının destek eğitim almaları 
konusunda istekli olmamaları veya böyle bir eğitim almaları için bir arayış içerisine girmemeleri şeklinde açıklanmıştır.

2. Ö̈̆gretmen Eğitimi Eksikliği: Okul öncesi öğretmenlerinin büyük bir çoğunluğu özel yetenekli öğrencilere nasıl eğitim verecekleri konusunda bilgisizdir. Bu nedenle çok geniş ranjda farklılık gösteren bu çocuklara yönelik eğitim programları hazırlamak konusunda yetersiz kalmaktadırlar. Özel eğitim gerektiren çocuklarla ilgili eğitim programlarına tabi tutulsalar bile bu öğretmenler sınıflarındaki özel yetenekli çocuklar için nasıl bir eğitim müdahalesi kullanacakları konusunda oldukça sınırlı bilgi edinmektedir. $\mathrm{Bu}$ da eğitim müdahalelerinin oluşturulması ve sürdürülmesinde önemli bir engel teşkil etmektedir.

3. Özel Yetenekli Öğrencilerin Eğitimcilerinin Daha Çok İleri Yaştaki Özel Yetenekli Öğrencilere Önem Vermesi: Özel yeteneklilere eğitim veren öğretmenler genel olarak büyük yaş grubundaki çocuklara yönelik eğitim süreçleri düzenlemede başarı göstermektedir. Çünkü öğretmenler büyük yaş gruplarındaki çocuklara eğitim programı hazırlarken kendilerini daha yeterli ve rahat hissetmektedir.

4. Ekonomik Kısıtlılık: Birçok okulun ekonomik nedenlerden ötürü, okul öncesi dönemde özel yetenek gösteren çocuklara yönelik erken müdahale programı uygulama konusunda bir girişimi bulunmamaktadır.

5. Yasal Düzenlemelerin Eksikliği: Özellikle de devlet okulları başta olmak üzere diğer engel gruplarında olduğu gibi özel yetenekli çocukların da erken müdahale hizmetlerinde faydalanmasını zorunlu kılan bir yasal düzenleme bulunmamaktadır.

$\mathrm{Bu}$ engellere rağmen alan yazında özel yetenekli çocuklara yönelik erken müdahale programları bulunmaktadır (Karnes \& Johnson, 1991). Bu programlara örnek teşkil edecek altı program aşağıda detaylı olarak verilmiştir.

\section{New Mexico State Üniversitesi Özel Yetenekliler Anaokulu}

○ Bu programda 3-5 yaş aralığındaki özel yetenekli çocuklar eğitim görmektedir.

- Çocuklar yarım günlük bir programda eğitim görmektedir.

- Bloom'un taksonomisi, Taba'nın tümevarım yöntemi, Swehman'ın sorgulama modeli ve Torrance'ın yaratıcı sorgulama modeli öğretim sürecinde aktif olarak kullanılmaktadır.

- Öğretim programının üç bileşeni: temel beceri geliştirme, tematik birimler ve çok kültürlü eğitimdir (Kitano \& Kerby, 1986).

\section{Astor Programı}

- Bu program, dört ve beş yaşındaki üstün yetenekli çocuklar için Virginia Ehrlich tarafından New York devlet okullarının bir parçası olarak geliştirilmiştir.

- Bu kurumsal program, üst düzey becerileri desteklemektedir.

- Programda Bloom'un taksonomisi, akademik beceriler ve yaratıcılık geliştirme çalışmaları yapılmaktadır (Ehrlich, 1980).

\section{Seattle Çocuk Gelişim Anaokulu}

- 1976 yılında Washington Üniversitesi’nde okul öncesi eğitimi uzmanı Halbert Robinson'un önderliğinde özel yetenekli çocukların eğitiminde araştırma ve program geliştirme merkezi olarak kurulmuştur.

- Bu programda çocuklar, yapılandırılmış etkinliklere göre dil sanatları, fen, matematik, sosyal beceriler, tiyatro, sanat ve yaratıcılık alanlarında yetenek seviyelerine göre gruplandırılırlar. 
- Buna ek olarak programda bağımsızlı̆̆ın, sosyal duyarlılığın, problem çözmenin, arkadaşlığın ve atılganlığın gelişmesini kolaylaştırmaya büyük önem verilmektedir (Robinson \& Roedell, 1980).

\section{Hunter College Anaokulu} programdir.

- Bu program okul öncesi dönemdeki çoğunluk ve azınlık gruplara aynı anda hizmet eden bir

- Çocuklar Stanford Binet zeka testinden aldıkları puanlara göre belirlenmektedir.

- Çocuklar yarım günlük bir programda eğitim görmektedir.

- Programdaki çocuklarının çoğunluk ve azınlık oranı 60:40'dır.

- Bu programda geleneksel akademik becerilerin yanı sıra ikinci bir dilin öğrenilmesi de vurgulanmaktadir.

- Bu programda bağımsız projeler ve birim etkinlikleri yer almaktadır (Camp, 1963).

\section{Pippi Programı}

- Bu program New York'taki Doğu Harlem'de uygulanmaktadır.

- Program, kültürel olarak çeşitlilik gösteren ve iki dilli olan özel yetenekli çocuklar için tasarlanmıştır.

- Program Fordham Üniversitesi Eğitim Fakültesi tarafindan, Bloom'un Taksonomisinin aktif şekilde kullanılarak organize edilmektedir.

- Buna ek olarak programda eleştirel düşünme, yaratıcı düşünme, mantıksal düşünme ve problem çözme becerilerinin geliştirilmesi üzerinde durulmaktadır.

- Bu programda ebeveyn katılımı çocukların gelişiminde programın kritik bir bileşeni olarak görülmektedir (Swassing, 1985).

\section{Illinois Üniversitesi Projeleri}

- Program 3-7 yaş aralığındaki çocukları kapsamaktadır.

- Eğitime rehberlik eden kavramsal modeller, İngiliz Bebek Okulundan "Açık Çerçeve" ve Guilford'un Mantık Yapısı (SOI)'ndan uyarlanmıştır.

- Genel olarak belirlenmiş bir eğitim programı yoktur.

- Her bir çocuğun eğitim programı çocuk ve öğretmen tarafından belirlenmektedir.

- Eğitim programının belirlenmesinde çocuğun ihtiyaçları ve yararı her şeyden önemlidir.

- Öğretmen, çocuğun öğrenmelerinde hiçbir eksik olmadığından emin olmalıdır.

- Her çocuk kendi kendine öğrenme hızına göre ilerlemektedir.

- Programın en önemli hedefleri, genç yetenekli çocukların kendi deneyimlerini, kendi çevrelerini ve duygularını anlamalarına yardımcı olmaktır.

- Diğer hedefleri ise çocukların kendi deneyimlerini keşfetmeleri, gözlem yapmaları, organize etmede araç olarak temel öğrenme becerilerini kullanmaları, çocukların başarma duygusunu güçlendirecek bilgi ve duygusal kaynakları geliştirmelerine yardımcı olmaktır (Karnes \& Johnson, 1991). 


\section{Özel Yetenekli Bireylere Erken Müdahale Programlarının Uygulanmasına Yönelik Çalışmalar}

Castillo (1998), tarafindan özel yetenekli olan ve olmayan 5-6 yaşındaki 63 çocukla yürütülen deneysel çalışmada, analoji kullanımı temele alınarak bir erken müdahale programı uygulanmıştır. Programın etkililiğini belirlemek amacıyla, analojileri açıklama, bu açıklamaları gerekçelendirme ve metafor yorumlama becerileri araştırmacı tarafından hazırlanan ölçme araçları ile ölçülmüştür. Bu programın, çalışmaya katılan tüm çocukların metaforları anlama becerilerini önemli ölçüde olumlu etkilediği sonucuna varılmıştır.

Gagne \& Gagnier (2004) tarafından yapılan çalışmada, okula erken başlamanın özel yetenekli çocukların sosyal entegrasyon ve akademik başarıları üzerindeki etkisi 2 yıllık boylamsal bir araştırma ile belirlenmiştir. Çalışmaya 98 özel yetenekli çocuk katılmış ve okula erken başlamaları sağlanmıştır. Çalışmadan elde edilen bulgular sonucunda, okula erken başlayan ve zamanında başlayan özel yetenekli çocukların sosyal entegrasyon ve akademik başarılarında anlamlı farklılık olmadığı görülmüştür.

Hanninen (1984), 3-5 yaş aralığındaki 66 özel yetenekli çocukla yürüttüğü çalışmada yaratıcılık temelli erken müdahale programının bireysel başarı ve yaratıcılık üzerindeki etkilerini incelemiştir. Çalışmada, bu becerileri ölçmek amacıyla PIAT (Peabody Individual Achievement Test) ve TTC (Torrance Test of Creativity) kullanılmıştır. Araştırmadan elde edilen bulgular sonuncunda, uygulanan programın özel yetenekli çocukların, PIAT'ın genel değerlendirme bölümünde ve Torrance'ın yaratıcılık, akıc1lı ve orijinallik bölümlerinde anlamlı düzeyde farklılaştığı görülmüştür.

Karnes \& Johnson (1987a), yaptıklanı çalışmada okul öncesi dönemdeki özel yetenekli çocuklara yönelik yaratıcılık temelli bir erken müdahale programı uygulamıştır. Programın etkililiğini belirlemek amaciyla Thinking Creatively in Action and Movement, K-ABC testinin 4 alt testi (Sihirli Daire, Yüz Tanıma, Gestalt ve İfade Edici Dil), Benlik Algısı ve Motivasyon ölçekleri kullanılmıştır. Kontrol gruplu deneysel desende yürütülen çalışmaya erken müdahaleden faydalanan ve faydalanmayan, özel yetenekli olan ve olmayan toplam 446 çocuk katılmıştır. Çalışma bulgularına göre, müdahale programında faydalanan çocuklar yapılan testlerde daha yüksek performans göstermiştir. Bununla beraber en fazla ilerleme müdahale programına katılan ancak özel yetenekli olarak tanımlanmayan çocuklarda kaydedilmiştir.

Karnes \& Johnson (1987b) 3-5 yaş aralı̆̆ındaki özel yetenekli olan ve olmayan 31 çocukla yürüttüğü çalışmada erken müdahale programının temelini Guilford ve SOI'nin yöntemlerinden oluşturmuştur. Çalışmanın temel amacı bu programın, çocukların okuma ve matematik becerilerinin üzerindeki etkisinin incelenmesidir. Çalışmada veri toplamak amacıyla Başarı ve Eğitsel Beceriler Testi ve Aile Görüşmeleri kullanılmıştır. Elde edilen bulgular, çocukların başarı ve eğitsel becerilerde anlamlı düzeyde farklılaştığını göstermiştir.

Karnes, Shwedel \& Lewis (1983a)'in okul öncesi dönemden 4. Sınıfa kadar yürüttükleri boylamsal çalışmada, okul öncesi dönemden itibaren 30 özel yetenekli çocuğa RAPYHT (Retrieval Acceleration of Promising Young Handicapped Talented) erken müdahale programını uygulamıştır. Programın temel amacı çocukların okuma ve matematik becerilerinin geliştirilmesidir. Araştırmada veri toplamak amacıyla Standardize Edilmiş Başarı Testleri ve Öğretmen Görüşmeleri kullanılmıştır. Elde edilen bulgular sonucunda özel yetenekli çocukların bu müdahale sayesinde her zaman akranlarından daha yüksek performans gösterdiği görülmüştür.

Karnes, Shwedel \& Lewis (1983b)'in, 4 yaşındaki 28 özel yetenekli, 8 normal gelişim gösteren çocukla yürüttüğü çalışmada yine RAPYHT erken müdahale programı uygunlamıştır. Ancak bu çalışmada programın, çocukların yetenek alanı işleyişi, benlik kavramı, yaratıcılık, görev sürekliliği özellikleri üzerindeki etkisi incelenmiştir. Veri toplamak amacıyla Adkins \& Ballif (1973) 
tarafından geliştirilen Animal Crackers'in iki alt testi, Torrance Yaratıcılık Testi ve Yetenek Kontrol Listesi kullanılmıştır. Çalışmaya katılan ve müdahale programından faydalanan özel yetenekli çocukların tamamının programdan faydalanmayan çocuklara göre, bu ölçme araçlarında anlamlı düzeyde yüksek performans gösterdiği sonucuna varılmıştır.

Meador (1994), yaş ortalamas1 5.7 olan ve hem deney $(n=23)$ hem kontrol grubunda $(n=41)$ özel yetenekli ve normal gelişim gösteren çocukların yer aldığı çalışmasında problem çözme temelli erken müdahale programı uygulamıştır. Programın etkililiğini ortaya koymak amacıyla yaratıcık için Torrance Testi (TTCT), benlik kavramı için (Martinek-Zaichkowsky Self-Concept Scale for Children) ve dil becerileri için Peabody Resimli Kelime Testi (Peabody Picture Vocabulary Test) kullanılmıştır. Elde edilen bulgulara göre, deney ve kontrol gruplarının benlik kavramı ve dil becerileri arasında anlamlı farklılık olmadığ 1 , ancak deney grubunun yaratıcılık puanlarının kontrol grubuna göre anlamlı düzeyde yüksek olduğu görülmüş̧ür. Müdahale programının temelini oluşturan problem çözme becerisinin geliştirilmesinin yaratıcıllğı doğrudan etkilediği göz önünde bulundurularak bu sonuç, alan yazınla paralellik göstermiştir. Ancak özel yetenekli olan ve olmayan, aynı zamanda müdahale programından faydalanan çocukların yaratıcılık puanları arasında anlamlı bir farklılık olmadığı görülmüştür.

Obrzut, Nelson \& Obrzut (1984)'un, 4.8-5.11 yaş aralığındaki 68 çocuklar yürüttüğü çalışmada, özel yetenekli çocukların okula erken başlamasının, akademik başarı (okuma, konuşma ve matematik) ve okula uyum süreci üzerindeki etkisi incelenmiştir. Çalışmada okul erken başlama düzeyinde olan ancak erken başlamayan ve okula erken başlama düzeyinde olmayan çocuklardan oluşan iki kontrol grubu bulunmaktadır. Çalışmada veri toplamak amacıyla WRAT (Wide Range Achievement Test), okul kayıtları, sağlık kayıtları, aile-öğretmen görüşmeleri ve anketleri kullanılmıştır. Elde edilen bulgulara göre deney sonrasında, okula erken başlayan çocuklar okuma, konuşma ve matematikte daha yüksek performans göstermiştir. Bununla birlikte deney ve kontrol grupları arasında sosyal olgunluk alanında anlamlı bir farklılık bulunamamıştır.

Rabinson, Abbott, Berninger, Busse \& Mukhopadhyay (1997) tarafindan, okul öncesi dönemdeki özel yetenekli çocuklarla 2 yıl süresince yürütülen çalışmada, kontrol grubu olarak normal gelişim gösteren çocuklar belirlenmiştir. Çalışmada yürütülen erken müdahale programının temelini matematiksel zenginleştirme oluşturmuştur. Çalışmada, programın görsel-uzamsal muhakeme ve matematiksel beceriler üzerine etkisi incelenmiştir. Araştırmada veri toplamak amaciyla Stanford-Binet IV'ün sayısal bölümü, Key-Math Testi'nin geometri ve problem çözme bölümü ile Woodcock Johnson Başarı Testi'nin hesaplama alt testleri kullanılmıştır. Müdahale programı sonrasında, deney grubunun verilen ölçeklerin tüm alt testlerinde daha yüksek ortalamalara sahip olduğu sonucuna varılmıştır.

Van Tassel-Baska \& Lipschutz (1982) tarafindan 4 yaş grubundaki 14 özel yetenekli çocukla yürütülen çalışmada, matematik, okuma ve alıcı dil becerileri üzerine odaklanan bireysel müdahale programının etkisi incelenmiştir. Çalışmada veri toplamak amacıyla WRAT, PPVT (Peabody Resimli Kelime Testi), Raven'ın Renkli Porgrasif Matrisler Testi ve ebeveyn görüşleri kullanılmıştır. Araştırmadan elde edilen bulgulara göre, birinci yılın sonunda WRAT testinden okumada \%35, matematikte $\% 85$, PPVT ve RAVEN Testi'nden ise \%64 daha yüksek puanlar alınmıştır. Ebeveynlerin \%100'ünden çocukların gelişimi ile ilgili olumlu geri bildirim alınmıştır.

Ülkemizde yapılan özel yetenekli çocuklara yönelik erken müdahale çalışmaları incelediğimizde, Bildiren (2016) tarafından yapılan doktora tezi çalışması ön plana çıkmaktadır. Bu çalışmada proje tabanlı erken müdahale programının özel yetenekli çocukların problem becerileri üzerine etkisi incelenmiştir. Çalışmada, özel yetenekli olarak tanımlanan öğrenciler 3 aşamada belirlenmiştir. Birinci aşamada aday gösterme ölçeği, 2. aşamada Metropolitan Okul olgunluğu Testi'nin sözel kısmı, 3. Aşamada ise bu tez kapsamında geçerlik ve güvenirlik çalışması yapılan RAVEN'in Renkli Prograsif Matrisler Testi kullanılmıştır. Özel yetenekli olarak belirlenen 44 çocuk 
deney ve kontrol grubunu oluşturmak üzere seçkisiz olarak belirlenmiştir. Daha sonra 4 ayrı temadan oluşan 12 haftalık proje tabanlı erken müdahale programı uygulanmıştır. Programın problem becerileri üzerine etkisini ölçmek amaciyla Problem Çözme Becerileri Ölçeği (Aydoğan, Ömeroğlu, Büyüköztürk, Özyürek, 2012) kullanılmıştır. Elde edilen bulgulara göre proje temelli erken müdahale programın, özel yetenekli çocukların problem çözme becerilerini arttırdığı ve bu beceri üzerinde kalıcı bir etki yarattığı tespit edilmiştir.

Saranlı (2017) tarafından yapılan çalışmada ise "Renzulli'nin Birinci Tip Zenginleştirme Yöntemine" dayanan ve farklılaştırılmış okul öncesi fen etkinliklerinin yer aldığı bir erken müdahale programı oluşturulmuştur. Araştırma nitel bir çalışma olup, veriler öğretmenlerin zenginleştirme yöntemini bir erken müdahale yöntemi olarak kullanmaları ile ilgili görüşlerinin alınması ile elde edilmiştir. $\mathrm{Bu}$ doğrultuda öğretmenlerden, uygulama sonrasında sınıflarındaki özel yetenekli çocuklarda gözlemledikleri farklılıkları belirtmeleri istenmiştir. Bulgular doğrultusunda öğretmenlerin zenginleştirme yöntemini okul öncesi dönem eğitim anlayışına ve uygun olduğunu düşündüğü sonucuna varılmıştır. Bununla birlikte bu modelin sınıf içinde normal gelişim gösteren çocukları da olumlu yönde etkilediği belirtilmiştir. Yurtiçi ve yurtdışında okul öncesi dönemdeki özel yetenekli bireylere yönelik erken müdahale programları üzerine yapılan araştırmalar incelendiğinde, çalışmaların oldukça sınırlı olduğu görülmüştür. Ancak özellikle bu alanda yapılan çalışmaların matematik, fen, okuma yazma gibi alanlarda akademik başarının arttırılması gibi konulardan ziyade düşünme becerilerinin geliştirilmesine yönelik çalışmalara yer verildiği görülmüştür.

\section{Sonuç ve Öneriler}

Okul öncesi dönemdeki özel yetenekli çocukların genel özellikleri (Cukierkorn, Karnes, Manning, Houston \& Besnoy, 2008) incelendiğinde birçok gelişim alanında akranlarına göre nispeten ileride oldukları görülmektedir. Bu durum diğer tüm gereksinim gruplarında olduğu gibi bu gruplarında erken müdahaleden faydalanmasına ortam sağlamaktadır. Erken çocukluk döneminde özel yetenekli çocukların eğitime duyduğu ihtiyaç üzerinde fikir birliği olmasına rağmen eğitimde en az hizmet alan gruplardan biri olduğu görülmektedir (Walsh, Kemp, Hodge \& Bowes, 2012). Bu nedenle diğer alanlara göre daha az erken müdahale modelleri yer almaktadır (Karnes \& Johnson, 1991).

Çalışma kapsamında incelenen erken müdahale programlarının (Bildiren, 2016; Camp, 1963; Ehrlich, 1978; Karnes \& Johnson, 1991; Kitano \& Kerby, 1986; Robinson \& Roedell, 1980; Swassing,1985) içeriğine bakıldığında Bloom taksonomi modelinin yaygın olarak kullanıldığı ve sorgulama, yaratıcı düşünme, eleştirel düşünme ile problem çözme becerilerini geliştirmeye yönelik içeriklerin oluşturulduğu görülmektedir. Bu becerilerin geliştirilmesine odaklanılması ile erken çocukluk döneminde, çocukların önde giden bilişsel gelişiminin desteklenmesi hedeflenmiştir (Karnes \& Johnson, 1991).

Ülkemizde özel yetenekliler için yapılan erken müdahale çalışmaları (Bildiren, 2016; Saranlı, 2017) incelendiğinde ise oldukça sınırlı sayıda başarılı çalışmalar yapıldığ 1 görülüştür. Bu durum ülkemiz için gerekli olan ihtiyacı ortaya çıkarmaktadır.

Özel yetenekliler için geliştirilen erken müdahale programlarında aşağıdaki unsurlar göz önünde bulundurulmalıdır (Castillo, 1998; Gagne \& Gagnier, 2004; Hanninen, 1984; Karnes \& Johnson, 1987a; Karnes \& Johnson, 1987b, Karnes, Shwedel \& Lewis, 1983a; Karnes, Shwedel \& Lewis, 1983b; Meador, 1994; Obrzut, Nelson \& Obrzut, 1984, Robinson, Abbott, Berninger, Busse \& Mukhopadhyay, 1997; Van Tassel-Baska \& Lipschutz, 1982):

- Geliştirilecek erken müdahale programlarında çocukların üst düzey düşünme becerilerini geliştirmek için Bloom'un taksonomisi, Taba'nın tümevarım yöntemi, Swehman'ın sorgulama modeli ve Torrance'ın yaratıcı sorgulama modeline yer verilmelidir. 
- Programlarda; temel beceri geliştirme, disiplinler arası yaklaşım, çok kültürlülük, sosyal duyarlılık, problem çözme, proje hazırlama, eleştirel düşünme, yaratıcı düşünme ve mantıksal düşünme becerilerinin geliştirilmesi ön planda olmalıdır. $\mathrm{Bu}$ nedenle özel yeteneklilere eğitim verilen okullar tüm çocuklarda amaçlı olarak üst düzey düşünme, problem çözme ve yaratıcı / üretken düşünme gelişimini desteklemelidir.

- Program içeriğinin belirlenmesinde çocuğun ihtiyaçları ve yararı her şeyden önemli olmalidir.

- Programın temel yapısı çocukların kendi deneyimlerini, kendi çevrelerini ve duygularını anlamlandırmaları üzerine kurulmalıdır.

- Programda ebeveyn katılımı çocukların gelişsiminde programın kritik bir bileşeni olarak görülmelidir. Bu nedenle erken çocukluk dönemindeki özel yetenekli çocuklar ile yapılacak çalışmalar yaş grubunun özellikleri nedeniyle ailelerden arını bir şekilde düşünülememelidir.

- Sosyoekonomik açıdan dezavantajlı grupların da yararlandığı bütüncül bir eğitim uygulaması sağlanmalıdır.

- Programların okulun bir parçası veya yarım günlük eğitim şeklinde uygulanabilir olmasına dikkat edilmelidir.

- Programlar sürekli olarak uygulanacak ve geri bildirim sağlayacak şekilde planlanmalıdır.

- Belirlenen okul öncesi dönemdeki özel yetenekli çocukların gelişimsel ve eğitsel ihtiyaçları belirlenmelidir.

- Yapılan ihtiyaç analizleri sonucunda özel yetenekli çocuklara yönelik erken müdahale programları hazırlanmalıdır.

- Hazırlanan erken müdahale programları ülke genelinde ancak çocuklar özelinde (bireysel olarak zenginleştirilmiş) uygulanan standart programlar haline getirilmelidir.

- Okul öncesi dönemdeki özel yetenekli çocuklara yönelik hazırlanabilecek erken müdahale çalışmalarına bilimsel veri sağlayacak deneysel çalışmalar yapılmalıdır.

- Okul öncesi dönemdeki özel yetenekli çocukları belirleme ve onlara yönelik müdahale programlarının etkililik düzeyine yönelik geri bildirimin sürekliliğinin sağlanması gerekmektedir.

- Özel yetenekli çocukların tanımlanması süreklilik arz eden bir süreç olmalıdır. Bu durum özellikle düşük gelirli ve azınlık gruplarından olan çocuklar için oldukça önemlidir. Çünkü bu çocukların zamana ve özel yeteneklerini sergileme firsatına ihtiyaçları vardır.

Ülkemizde henüz okul öncesi dönemde özel yetenekli çocukların tanılanması ve bir müdahale programı uygulanmasının taahhüt edilmemiş olması nedeniyle özel yeteneklilerin eğitiminde erken müdahale eksik kalmaktadır. Bu doğrultuda özel yetenekli çocukların erken dönemde tanılanmasını ve eğitim sağaltımının sağlanması üzerine çalışmalar yapılması gerekmektedir. Özellikle devlet okullarında 5 yaş ve daha küçük çocukların zorunlu olarak eğitilmesinin yasal zemini oluşturulmalıdır.

\section{Kaynakça}

Abroms, K.I. \& Gollin, J.B. (1980). Developmental study of gifted preschool children and measures of psychosocial giftedness. Exceptional Children, 46(5), 334- 337.

Abroms, K.I. (1981). Birth cry to five: Milestones in the psychosocial development of the gifted. Paper presented at the Annual International Convention of The Council for Exceptional Children. (ERIC Document Reproduction Service No. ED209820). 
Barbour, N. E. (1992). Early childhood gifted education: A collaborative perspective. Journal for the Education of the Gifted, 15, 145-162.

Barbour, N. E., \& Shaklee, B. D. (1998). Gifted education meets Reggio Emilia: Visions for curriculum in gifted education for young children. Gifted Child Quarterly, 42,228-238.

Belova, E. S. (2019). Young gifted children and microenvironment of their development. journal of international scientific publications: language, individual \& society, 13, 117-123.

Bildiren, A. (2016). Proje temelli yaklaşıma dayalı erken müdahale programının üstün yetenekli çocukların problem çözme becerisine etkisi. Doktora Tezi, Ankara Üniversitesi, Eğitim Bilimleri Enstitüsü.

Bildiren, A., \& Kargin, T. (2019). The Effects of Project Based Approach in Early Intervention Program on the Problem Solving Ability of Gifted Children. Egitim ve Bilim, 44(198).

Bishop, D. V., Price, T. S., Dale, P. S., \& Plomin, R. (2003). Outcomes of early language delay: II. Etiology of transient and persistent language difficulties. Journal of Speech, Language, and Hearing Research, 46(3), 561-575.

Bloom, B.S., (1964). Stability and change in human characteristics. Wiley.

Bredekamp, S., \& Copple, C. (Eds.). (1997). Developmentally appropriate practice in early childhood programs. Washington, DC: National Association for the Education of Young Children.

Bullock, M., Gelman, R., \& Baillargeon, R. (1982). The development of causal reasoning. The developmental psychology of time, 209-254.

Bullmore, E., Serra-Grabulosa, J., Romero-Garcia, R., Vilaseca, G., Adan, A., Vilaró, N., \& Bargalló, N. (2019). Structural brain network of gifted children has a more integrated and versatile topology.

Camp, L. (1963). Purposeful preschool education. Gifted Child Quarterly, 7, 106-7.

Castillo, L. C. (1998). The effect of analogy instruction on young children's metaphor comprehension. Roeper Review, 21, 27-31.

Chamrad, D. L., \& Robinson, N. M. (1986). Parenting the intellectually gifted preschool child. Topics in Early Childhood Special Education, 6(1), 74-87.

Clark, B. (2002). Growing up gifted (6. Bask1). Merrill: Upper Saddle River, NJ.

Cherny, S. S., Fulker, D. W., Emde, R. N., Plomin, R., Corley, R. P., \& DeFries, J. C. (2001). Continuity and change in general cognitive ability from 14 to 36 months. İçinde R. N. Emde $\&$ J. K. Hewitt (Eds.), Infancy to early childhood: Genetic and environmental influences on developmental change (ss. 206-220). Oxford University Press.

Clark, G., \& Zimmerman, E. (2004). Teaching talented art students: Principles and practices. Teachers College Press.

Clark, B. (2013). Growing up gifted: Developing the potential of children at school and at home (8th ed.). Pearson.

Coates, D., Thompson, W., \& Shimmin, A. (2008). Using learning journeys to develop a challenging curriculum for gifted children in a nursery (Kindergarten) setting. Gifted and Talented International, 23(1), 97-104. 
Creel, C., \& Karnes, F. A. (1988). Parental expectations and young gifted children. Roeper Review, $11,48-50$.

Cross, T. (2017). On the social and emotional lives of gifted children. Sourcebooks, Inc.

Cukierkorn, J. R., Karnes, F. A., Manning, S. J., Houston, H., \& Besnoy, K. (2008). Recognizing giftedness: Defining high ability in young children. Dimensions of early childhood, 36(2), 3-13.

Damiani, V.B. (1997). Young gifted children in research and practice. Gifted Child Today Magazine, 20(3), 18-23.

Deater-Deckard, K., \& Cahill, K. (2006). Nature and nurture in early childhood. İçinde Handbook of early childhood development, ss 3-21, Blackwell Publishing: Cornwall, United Kingdom.

Eby, J.W., \& Smutny, J.F. (1991). A thoughtful overview of gifted education. Longman: New York.

Ehrlich, V. (1978). The Astor program for gifted children: Prekindergarten strategies, grade three. Teachers College, Columbus University.

Ehrlich, V. Z. (1985). Gifted children: A guide for parents and teachers. Trillium Press.

Emre, O. (2017). Çocuk Gelişimi Gelişim Psikolojisinin Temel Esasları II. Anı Yayıncılık.

Feldhusen, J.F., \& Kolloff, M.B. (1979). Giftedness: A mixed blessing for the preschool child. İçinde S.M. Long, \& B. Batchelor (Eds.). When there is crisis: Helping children cope with change. Terre Haute, IN: Indiana Association for the Education of Young Children.

Gagné, F. Y., \& Gagnier, N. (2004). The socio-affective and academic impact of early entrance to school. Roeper Review, 26, 128-138.

Gelman, S. A., \& Markman, E. M. (1986). Categories and induction in young children. Cognition, 23, 183-209.

Ginsburg, H. P., \& Golbeck, S. L. (2004). Thoughts on the future of research on mathematics and science learning and education. Early Childhood Research Quarterly, 19(1), 190-200.

Gould, J. C., Thorpe, P., \& Weeks, V. (2001). An early childhood accelerated program. Educational Leadership, 59(3), 47-50.

Gross, M.U.M. (1993). Exceptionally gifted children. Routledge.

Gross, M.U.M. (1999). Small poppies: Highly gifted children in the early years. Roeper Review, 21(3), 207-215.

Guralnick, M. J. (2019). Effective Early Intervention: The Developmental Systems Approach. Brookes Publishing Company.

Guralnick, M. J., \& Bruder, M. B. (2019). Early intervention. In Handbook of Intellectual Disabilities (pp. 717-741). Springer, Cham.

Hall, E. G., \& Skinner, N. (1980). Somewhere to turn: Strategies for parents of gifted and talented children. Teachers College Press.

Hanninen, G. E. (1984). Effectiveness of a preschool program for the gifted and talented. Journal for the Education of the Gifted, 7, 192-204.

Harrison, C. (1999). Giftedness in early childhood. Gifted Education Research Resource and Information Centre.

Harrison, C. (2003). Giftedness in early childhood (3rd ed.). NSW: GERRIC. 
Harrison, C. (2004). Giftedness in early childhood: The search for complexity and connection. Roeper Review, 26(2), 78-84.

Hertzog, N. B., Klein, M. M., \& Katz, L. G. (1999). Hypothesizing and theorizing: Challenge in an early childhood curriculum. Gifted and Talented International, 14, 38-49.

Hertzog, N. B. (2003). Impact of gifted programs from the students' perspectives. Gifted Child Quarterly, 47(2), 131-143.

Hodge, K. A., \& Kemp, C. R. (2000). Exploring the nature of giftedness in preschool children. Journal for the Education of the Gifted, 24, 46-73.

Hodge, K. A. (2013). Young gifted children: What do their preschool and childcare educators believe and do? Paper presented at the Giftedness in Early Childhood: Insights from Research and Practice Conference, Macquarie University.

Hunt (1961). Intelligence and experience. Ronald Press.

Jackson, N. (2003). Young gifted children. İçinde N. Colangelo \& G.A. Davis (Ed.). Handbook of gifted education (3. Bask1, ss. 470-482). Allyn \& Bacon.

Jacobs, J.C. (1971). Rorschach studies reveal possible misinterpretations of personality traits of the gifted. Gifted Child Quarterly, 15(3), 195-200.

Justice, L. M., \& Kaderavek, J. N. (2004). Embedded-explicit emergent literacy intervention I: Background and description of approach. Language, Speech, and Hearing Services in Schools, 35(3), 201-211.

Kaplan, S., \& Hertzog, N. B. (2016). Pedagogy for early childhood gifted education. Gifted Child Today, 39(3), 134-139.

Karnes, M. B., \& Johnson, L. J. (1987a). Bringing out Head Start talents: Findings from the field. Gifted Child Quarterly, 31, 174-179.

Karnes, M. B., \& Johnson, L. J. (1987b). An imperative: Programming for the young gifted/ talented. Journal for the Education of the Gifted, 10, 195-214.

Karnes, M. B., Shwedel, A. M., \& Lewis, G. F. (1983a). Long-term effects of early programming for the gifted/talented handicapped. Journal for the Education of the Gifted, 6, 266-278.

Karnes, M. B., Shwedel, A. M., \& Lewis, G. F. (1983b). Short-term effects of early programming for the young gifted handicapped child. Exceptional Children, 50, 103-109.

Karnes, M. B., \& Johnson, L. J. (1991). The preschool/primary gifted child. Journal for the Education of the Gifted, 14(3), 267-283.

Karnes, F. A., Manning, S., Besnoy, K., Cukierkom, J., \& Houston, H. (2005). Appropriate practices for screening, identifying, and serving gifted preschoolers. Hattiesburg: The University of Southern Mississippi, The Frances A. Karnes Center for Gifted Studies.

Kennedy, M., Fisher, M. B., \& Ennis, R. H. (1991). Critical thinking: Literature review and needed research. In L. Idol \& B.F. Jones (Eds.), Educational values and cognitive instruction: Implications for reform (pp. 11-40). Hillsdale, New Jersey: Lawrence Erlbaum \& Associates.

Kingore, B. (2001). Great Books: Gifted Kids, Gifted Characters, and Great Books. Gifted Child Today, 24(1), 30-32.

Kitano, M. K. (1985). Ethnography of a preschool for the gifted: What gifted young children actually do. Gifted Child Quarterly, 29(2), 67-71. 
Kitano, M., \& Kirby, D. (1986). Gifted education: A comprehensive view. Boston, MA: Little, Brown and Company.

Kitano, M.K. (1990). Intellectual abilities and psychological intensities in young children: Implications for the gifted. Roeper Review, 13(1), 5-11.

Klein, P.S. (1992). Mediating the development of precocious young children. In P.S. Klein \& A.J. Tannenbaum (Eds.). To be young and gifted (pp. 245-277). Norwood, NJ: Ablex.

Koshy, V., \& Robinson, N. M. (2006). Too long neglected: Gifted young children. European Early Childhood Education Research Journal, 14, 113-126. http://dx.doi.org/10.1080/ 135029302 85209951

Louis, B., \& Lewis, M. (1992). Parental beliefs about giftedness in young children and their relation to actual ability level. Gifted Child Quarterly, 36(1), 27-31.

Magnuson, K. A., Meyers, M. K., Ruhm, C. J., \& Waldfogel, J. (2004). Inequality in preschool education and school readiness. American educational research journal, 41(1), 115-157.

Margrain, V., \& Lundqvist, J. (2019). Talent Development in Preschool Curriculum and Policies: Implicit Recognition of Young Gifted Children. In Challenging Democracy in Early Childhood Education (pp. 41-55). Springer.

McCartney, K., Harris, M. J., \& Bernieri, F. (1990). Growing up and growing apart: A developmental meta-analysis of twin studies. Psychological bulletin, 107(2), 226.

Meador, K. S. (1994). The effects of synectics training on gifted and nongifted kindergarten students. Journal for the Education of the Gifted, 18, 55-73.

Miller, E., \& Almon, J. (2009). Crisis in the kindergarten: Why children need to play in school. College Park, MD: Alliance for Childhood.

Morelock, M.J., Brown, P.M., \& Morrissey, A.M. (2003). Pretend play and maternal scaffolding: Comparisons of toddlers with advanced development, typical development, and hearing impairment. Roeper Review, 26(1), 41-51.

Morkoç, Ö. Ç., \& Acar, E. A. (2014). 4-5 yaş grubu çocuklarına yönelik çok amaçlı erken müdahale programı'nın etkililiğinin belirlenmesi. Kuram ve Uygulamada Eğitim Bilimleri, 14 (5), 1835-1860, https://dx.doi.org/10.12738/estp.2014.5.2065

Nicolopoulou, A., Barbosa de Sa, A., Ilgaz, H., \& Brockmeyer, C. (2009). Using the transformative power of play to educate hearts and minds: From Vygotsky to Vivian Paley and beyond. Mind, Culture, and Activity, 17(1), 42-58.

Obrzut, A., Nelson, R. B., \& Obrzut, J. E. (1984). Early school entrance for intellectually superior children: An analysis. Psychology in the Schools, 21, 71-77.

Olszewski-Kubilius, P., Limburg-Weber, L., \& Pfeiffer, S. (2003). Early gifts: Recognizing and nurturing children's talent. Prufrock Press: Waco, TX.

Perez, G.S. (1980). Perceptions of the young gifted child. İçinde R. Brodsky (Ed.). The young gifted child. Roeper Review, 3(2), 5-17.

Perleth, C., Lehwald, G., \& Browder, C.S. (1993). Indicators of high ability in young children. In K.A. Heller, F.J. Mönks, \& A.H. Passow (Eds.). International handbook of research and development of giftedness and talent (pp. 283-310). Elmsford. 
Petrill, S. A., Plomin, R., Berg, S., Johansson, B., Pedersen, N. L., Ahern, F., \& McClearn, G. E. (1998). The genetic and environmental relationship between general and specific cognitive abilities in twins age 80 and older. Psychological Science, 9(3), 183-189.

Peyre, H., Ramus, F., Melchior, M., Forhan, A., Heude, B., Gauvrit, N., \& EDEN Mother-Child Cohort Study Group. (2016). Emotional, behavioral and social difficulties among high-IQ children during the preschool period: Results of the EDEN mother-child cohort. Personality and Individual Differences, 94, 366-371.

Phillips, M. N. (1997). In the classroom: Doing what comes naturally. Gifted Child Today, 20(2), 26. 50.

Pianta, R. C., Barnett, W. S., Burchinal, M., \& Thornburg, K. R. (2009). The effects of preschool education: What we know, how public policy is or is not aligned with the evidence base, and what we need to know. Psychological science in the public interest, 10(2), 49-88.

Piechowski, M.M. (1992). Emotional development and emotional giftedness. In N. Colangelo \& G.A. Davis (Eds.). Handbook of gifted education (pp. 285- 305). Boston: Allyn \& Bacon.

Plomin, R., Asbury, K., \& Dunn, J. (2001). Why are children in the same family so different? Nonshared environment a decade later. The Canadian Journal of Psychiatry, 46(3), 225-233.

Porter, L. (1999). Gifted young children. Allen and Unwin, St Leonards.

Ramey, S.L., \& Ramey, C.T. (1992). Early educational intervention with disadvantaged children-To what effect? Applied and Preventive Psychology, I, 131-140.

Ramey, C. T., \& Ramey, S. L. (1996). Early intervention: Optimizing development for children with disabilities and risk conditions. In M. Wolraich (Ed.), Disorders of development and learning: A practical guide to assessment and management (2nd ed., pp, 141 - 158). Mosby.

Ramey, C. T., \& Haskins, R. (1981). The modification of intelligence through early experience. Intelligence, 5(1), 5-19.

Ramey, C. T., \& Ramey, S. L. (1998). Early intervention and early experience. American psychologist, 53(2), 109.

Richert, E. S. (2003). Excellence with justice in identification and programming. In N. Colangelo \& G. A.Davis (Eds.), Handbook of gifted education (3rd ed., pp. 146-158). Allyn \& Bacon.

Robinson, H., \& Roedell, W. (1980). Child development preschool. İçinde Educating the preschool/primary gifted and talented. National/ state leadership training instituted on the gifted and the talented, 237-41. Ventura, CA: Office of the Ventura County Superintendent of Schools.

Robinson, N. M. (1993). Parenting the very young gifted child. Parenting researchbased decision making series. Storrs, CT: National Research Center on the Gifted and Talented. (ERIC Document Reproduction Service No. ED301985).

Robinson, N. M. (2000). Giftedness in very young children: How seriously should it be taken? In R. C.

Friedman \& B. M. Shore (Eds.), Talents unfolding: Cognition and development (pp. 7-26).: American Psychological Association.

Robinson, N. M. (2008). Early childhood. In J. A. Plucker \& C. M. Callahan (Eds.), Critical issues and practices in gifted education: What the research says (pp. 179-194). Prufrock Press. 
Roedell, W. C. (1989). Early development of gifted children. In J. VanTassel-Baska \& P. OlszewskiKubilius (Eds.), Patterns of influence on gifted learners: The home, the self, the school (pp. 13-28). Teachers College Press.

Roedell, W. C., Jackson, N. E., \& Robinson, H. B. (1980). Gifted young children. Teachers College Press.

Roeper, A. (1977). The young gifted child. Gifted Child Quarterly, 21(3), 388-96.

Rotigel, J.V. (2003). Understanding the young gifted child: Guidelines for parents, families, and educators. Early Childhood Education Journal, 30(4), 209-214.

Saranlı, A. G. (2017). Okul öncesi dönemdeki erken müdahale uygulamalarına farklı bir bakış: Üstün yetenekli çocuklar için erken zenginleştirme. Eğitim ve Bilim, 42(190), 343-359. http://dx.doi.org/10.15390/EB.2017.7062

Scarr, S., \& McCartney, K. (1983). How people make their own environments: A theory of genotype $\rightarrow$ environment effects. Child development, 424-435.

Schnur, J. O., \& Lowrey, M. A. (1986). Some characteristics of precocious readers. Early Child Development and Care, 26(3-4), 191-198.

Schwartz, L. L. (1994). Why give "gifts" to the gifted? Investing in a national resource. Thousand, Corwin Press.

Shurkin, J.N. (1992). Terman kids: A ground-breaking study of how the gifted grow up. Little Brown.

Siegler, R.S., \& Alibali, M.W. (2004). Children's Thinking, 4. Baskı. Upper Saddle River: Prentice Hall.

Silva, E. (2009). Measuring skills for 21st-century learning. Phi Delta Kappan, 90(9), 630-634.

Snowden, P. L. (1995). Educating young gifted children. Gifted Child Today, 18(6), 16-21, 24-25,41.

Solé-Casals, J., Serra-Grabulosa, J. M., Romero-Garcia, R., Vilaseca, G., Adan, A., Vilaró, N., ... \& Bullmore, E. T. (2019). Structural brain network of gifted children has a more integrated and versatile topology. Brain Structure and Function, 224(7), 2373-2383.

Spearman, C. (1927). The abilities of man. Macmillan.

Sutherland, M. J. (2008). Developing the gifted and talented young learner. Sage.

Swassing, R. (1985). Teaching gifted children and adolescents. Charles E. Merrill.

Tannenbaum, A. (1992). Early signs of giftedness: Research and commentary. Journal for the Education of the Gifted, 15(2), 104-133.

Terman, L.M. (1925). Genetic studies of genius. Volume 1: Mental and physical traits of a thousand gifted children. Stanford University Press.

Tittle, B. M. (1984). Why Montessori for the gifted? Gifted Child Today, 33, 3-7.

Tucker, B., \& Hafenstein, N.L. (1997). Psychological intensities in young gifted children. Gifted Child Quarterly, 41,(3), 66-75.

Tuttle, F. B., Becker, L. A., \& Sousa, J. A. (1988). Characteristics and identification of gifted and talented students (3rd ed.). National Education Association of the United States.

VanTassel-Baska, J., Schuler, A., \& Lipschutz, J. (1982). An experimental program for gifted four year olds. Journal for the Education of the Gifted, 5, 45-55. 
Walker, B., Hafenstein, N. L., \& Crow-Enslow, L. (1999). Meeting the needs of gifted learners in the early childhood classroom. Young Children, 54(1), 32-36.

Walsh, R. L., Hodge, K. A., Bowes, J. M., \& Kemp, C. R. (2010). Same age, different page: Overcoming the barriers to catering for young gifted children in prior-to-school settings. International Journal of Early Childhood, 42(1), 43-58.

Walsh, R. L., Kemp, C. R., Hodge, K. A., \& Bowes, J. M. (2012). Searching for evidence-based practice: A review of the research on educational interventions for intellectually gifted children in the early childhood years. Journal for the Education of the Gifted, 35(2), 103128.

Walsh, R. L. (2014). Catering for the needs of intellectually gifted children in early childhood: Development and evaluation of questioning strategies to elicit higher order thinking. Doktora Tezi, Macquarie University, Institute of Early Childhood.

Webb, J. T., Meckstroth, E. A., \& Tolan, S. S. (1982). Guiding the gifted child: A practical guide for parents and teachers. Ohio Psychology.

Weikart, D. P. (1998). Changing early childhood development through educational intervention. Preventive Medicine, 27(2), 233-237.

Wechsler, D. (2002). Wechsler preschool and primary scale of intelligence (3rd ed.). The Psychological Corporation.

Winner, E. (1996). Gifted children (Vol. 1). Basic Books. 